\title{
Microdiálisis de alta resolución. Aspectos metodológicos y aplicación al estudio de la respuesta inflamatoria cerebral
}

\author{
J.A. De Los Rios*; J. Sahuquillo***; M.A. Merino*; M.A. Poca*,** y L. Expósito***
}

Unidad de Investigación de Neurotraumatología y Neurocirugía (UNINN)*. Servicio de Neurocirugía**. Unidad de Cuidados Intensivos de Neurotraumatología***. Hospital Universitario Vall d'Hebron. Institut Fundació de Recerca Vall d'Hebron. Universidad Autónoma de Barcelona.

\section{Resumen}

La técnica de microdiálisis (MD) cerebral es un instrumento que proporciona información relevante en la monitorización del metabolismo cerebral en pacientes neurocríticos. La MD es una técnica especialmente efectiva para la detección y análisis de pequeñas moléculas, puesto que el tamaño de los poros de la membrana dializante actúa como barrera restringiendo el paso de especies mayores, tales como proteínas u otras macromoléculas. La reciente disponibilidad de catéteres de microdiálisis con poros de mayor calibre, denominados de "alta resolución", permite ampliar el rango de moléculas detectables en el dializado. Sin embargo, existen complicaciones técnicas relacionadas con la utilización de estos catéteres para estos propósitos, por lo que esta capacidad potencial para la recuperación de proteínas necesita ser validada antes de su aplicación como herramienta para estudios de proteómica asociados a la lesión cerebral. En esta revisión se contemplan los principios básicos de la microdiálisis y los diferentes factores que intervienen en los procesos de recuperación de moléculas en el dializado, tales como las características físicas de la membrana dializante, así como de las moléculas que se desea investigar.

PALABRAS CLAVE: Microdiálisis. Punto de corte de membrana. Recuperación relativa. Citocinas. Quimiocinas. Neuroinflamación. Traumatismo craneoencefálico.

High Resolution Microdialysis. Methodological issues and application to the study of inflammatory brain response

\section{Summary}

Cerebral microdialysis is a tool that provides very relevant information in the metabolic monitoring of brain injured patients. It is a particularly effective

Recibido: 14-07-08. Aceptado: 9-02-09 technique for the detection and analysis of small molecules, given that the pores of the dialysis membrane act as a barrier to restrict the transport of larger species, such as proteins and other macromolecules. The recent availability of microdialysis catheters with membrane pores of larger size, termed "high resolution" catheters, would widen the spectrum of molecules detectable in the dialisate. However, there are technical complications related to the use of these catheters for such purposes, and therefore, this potential capacity for the recovery of proteins needs to be validated, in order to begin its application as a tool in studies of proteomics associated with brain injuries. The following review depicts the basic principles of microdialysis, and describes some of the issues involved in the recovery of molecules in the dialisate, including the physical properties of the dialysis membrane and of the molecules of interest.

Abreviaturas. BHE: barrera hematoencefálica. Cd: concentración del analito en el dializado. Ce: concentración del analito en el exterior del catéter. $\mathrm{cm} \mathrm{H}_{2} \mathrm{O}$ : centímetros de agua, unidad de presión. cut-off: punto de corte de peso molecular. D: difusividad, coeficiente de difusión. EE: eficiencia de extracción (extraction efficiency). Estándar: solución de concentración conocida de las proteinas purificadas. FMF: fuerza neta de movimiento de flujo. H: altura; Presión hidrostática. IL: interleucina. J, Jv: flujo neto. kDa: kilo Daltons, unidad de peso molecular. Kf: permeabilidad de la membrana (constante de filtración). LCR: líquido cefalorraquídeo. LPS: lipopolisacárido bacteriano. MD: microdiálisis. mmHg: milímetros de mercurio. mmol: milimoles. MMP: metaloproteasa de matriz. nm: nanometros. PDB: base de datos de proteinas (Protein Data Bank). PES: polietersulfona. $P M$ : peso molecular. $R d$ : resistencia a la difusión cerniente al dializado. Re: resistencia a la difusión cerniente al exterior de la membrana. Rm: resistencia a la difusión cerniente a la membrana. RR: recuperación relativa. SEM: microscopía electrónica de barrido. TCE: traumatismo craneoencefálico. TNF : factor de necrosis tumoral-alfa. Tri-foil: estructura terciaria de triple hoja. 
KEY WORDS: Microdialysis. Membrane cut off. Relative recovery. Cytokines. Chemokines. Neuroinflammation. Traumatic brain injury.

\section{Introducción}

El impacto mecánico en un traumatismo craneoencefálico grave (TCEG) desencadena una serie de cambios neuroquímicos, que en parte corresponden a procesos celulares y moleculares vinculados a una respuesta inflamatoria. Esta respuesta tiene, por un lado, el propósito de proteger y reparar el tejido dañado, pero por otro, acarrea consecuencias nocivas debido a la liberación de sustancias neurotóxicas. La cascada neuroinflamatoria que surge a raíz de estos acontecimientos puede exacerbar el daño neurológico y se incluye dentro de una categoría de procesos que, en conjunto, se conocen como lesión secundaria ${ }^{19}$.

La respuesta inmune, y por lo tanto, la respuesta inflamatoria cerebral, implica a células linfoides, células inflamatorias y al sistema hematopoiético. Las interacciones entre todas estas células está modulada por un grupo de proteínas mensajeras denominadas citocinas (CKs), cuya principal actividad es la de conectar a las distintas células implicadas en la repuesta inmune. Entre sus múltiples funciones, estas proteínas de bajo peso molecular aumentan la permeabilidad vascular, la permeabilidad de la barrera hematoencefálica (BHE), inducen la formación de edema, la expresión de moléculas de adhesión e infiltración celular y la amplificación de la expresión de otros mediadores proinflamatorios. Además de estas funciones, las CKs ejercen efectos directos sobre las neuronas y las células gliales activando procesos potencialmente deletéreos. Como parte del proceso neuroinflamatorio, se sobreexpresan también un grupo de proteasas neutras, las denominadas metaloproteasas de matriz (MMP), y particularmente la MMP-2 y MMP-9, también conocidas como gelatinasas ${ }^{100}$. Las gelatinasas juegan un papel importante en la alteración de la permeabilidad de la BHE mediante la degradación de la membrana basal ${ }^{70,76}$.

El conocimiento más detallado de las interacciones entre las distintas moléculas implicadas en la cascada neuroinflamatoria podría ayudar a una mejor comprensión de los procesos fisiopatológicos implicados en la lesión secundaria. Esto permitiría identificar nuevas opciones terapéuticas destinadas a limitar el empeoramiento de las lesiones y a mejorar la mortalidad y el pronóstico funcional de los pacientes que sobreviven a un TCEG.

Uno de los métodos más potentes para obtener información acerca de la presencia y concentración de estas moléculas en el tejido cerebral es la microdiálisis (MD). Esta técnica se ha convertido en los últimos años en una herramienta excelente para el desarrollo de proyectos de investigación traslacional en neurociencias. La MD se uti- liza en la actualidad como técnica para la monitorización de la bioquímica tisular de cualquier tejido, incluido el cerebral, y tiene un amplio espectro de aplicación en diversas especialidades clínicas. Esta técnica es especialmente relevante en el contexto del paciente neurocrítico, donde la MD permite documentar los cambios metabólicos regionales que ocurren en el cerebro lesionado ${ }^{16,18,34,43,44,94,97}$.

Hasta muy recientemente, la microdiálisis sólo permitía el análisis de metabolitos y de sustancias hidrosolubles de bajo peso molecular (PM). El tamaño de poro de la membrana actúa como factor limitante a la hora de seleccionar el espectro molecular final del dializado. Los catéteres de MD disponibles comercialmente hasta hace poco se construían con membranas con un punto de corte (cut-off) de $20 \mathrm{kDa}$ (CMA 70 Microdialysis, Solna, Suecia). El denominado "cut-off" se define como el peso molecular (PM) expresado en Daltons a partir del cual el $80 \%$ de las moléculas no atraviesan la membrana dializante. Por este motivo, los grupos de investigación interesados en moléculas más complejas, tanto en estructura como en PM, debían diseñar sus propias membranas adaptándolas a sus necesidades ${ }^{107}$. La reciente disponibilidad comercial de catéteres de MD con membranas de mayor tamaño de poro (100 kDa) ha ampliado el repertorio de sustancias analizables en el microdializado, permitiendo la posibilidad de determinar niveles in vivo de moléculas de gran interés en el estudio de diversas patologías, incluidas, entre otras, diversas proteínas, como las CKs. Maurer et al. ${ }^{61}$, utilizando membranas de $20 \mathrm{kDa}$, detectaron hasta diez proteínas en el microdializado cerebral de pacientes con un ictus isquémico que no fueron detectadas en el liquido cefalorraquídeo (LCR).

La MD aplicada al estudio de las proteínas existentes en el espacio intersticial cerebral (EIC) puede aportar un conocimiento mucho más profundo de las complejas interacciones moleculares que tienen lugar en el parénquima cerebral lesionado. Sin embargo, las propiedades de estas proteínas, tales como su tamaño, su forma, y la distribución heterogénea de sus cargas eléctricas, provocan diferencias importantes en la recuperación de estas moléculas en el microdializado cuando se compara con analitos de menor complejidad molecular.

Entre las proteínas que generan un mayor interés en el estudio de procesos inflamatorios en la lesión cerebral aguda se encuentran una serie de moléculas con especial relevancia en la respuesta inflamatoria cerebral, las denominadas citocinas, y entre ellas las quimiocinas e interleucinas (ILs). La IL1 $\beta$, la IL6 y el factor de necrosis tumoral $\alpha(\mathrm{TNF} \alpha)$ son moléculas implicadas en la activación de la respuesta inflamatoria precoz innata. La IL10 tiene en cambio una actividad anti-inflamatoria y la IL8 pertenece a la familia de las quimiocinas, implicadas en la migración de leucocitos desde el torrente circulatorio hacia la zona lesionada. Por otro lado, las gelatinasas están involucradas 
en la degradación de la BHE.

Todas estas moléculas tienen pesos moleculares por debajo del cut-off nominal de la membrana de $100 \mathrm{kDa}$ y son por lo tanto potencialmente recuperables por MD. Sin embargo, este hecho por si sólo, no garantiza su paso a través de la membrana dializante. Las moléculas de mayor tamaño tienen evidentemente menores coeficientes de difusión, pero su estructura terciaria/cuaternaria puede provocar, al entrar en contacto o atravesar los poros de la membrana dializante, el bloqueo de algunos de estos poros por adsorción proteica y restringir por lo tanto su difusión ${ }^{83}$. Cada proteína posee características únicas que condicionan su difusión y su paso a través de la membrana de MD.

Los estudios de recuperación relativa (RR) con membranas de microdiálisis son pues indispensables para valorar los niveles reales de las proteínas de interés en el tejido monitorizado. Nuestra unidad inició el estudio de la respuesta inflamatoria en el TCEG en el año 2004, coincidiendo con la aparición en el mercado de las membranas de $100 \mathrm{kDa}$. Durante este proceso, encontramos una serie de dificultades que se fueron resolviendo a partir de una revisión exhaustiva de la literatura y de experimentos in vitro. El propósito de esta revisión es aportar información de utilidad para aquellos clínicos que quieran iniciar el estudio de moléculas de mayor complejidad utilizando estas membranas. Aunque nuestros estudios se fundamentan en pacientes con un TCEG, los resultados aquí presentados son extrapolables a cualquier tipo de lesión cerebral, y los principios básicos, a cualquier tipo de molécula.

\section{Microdiálisis de alta resolución y concepto de recupe- ración relativa}

En los siguientes apartados se revisan los fundamentos teóricos de las técnicas de microdiálisis y de la recuperación de algunas moléculas a través de membranas de MD de alta resolución. Por MD de alta resolución entendemos la microdiálisis aplicada a la recuperación de moléculas de alto PM y/o de PM intermedio pero de estructura o carga que dificultan su recuperación. En este contexto es importante introducir el concepto de recuperación relativa (relative recovery o $R R$ ). Este término hace referencia a la concentración de la molécula de interés detectada en el microdializado, expresada como porcentaje de su concentración real en el tejido cerebral o en la solución in vitro que se desea estudiar. La RR se rige por distintos factores tales como las propiedades del poro de la membrana, la velocidad de perfusión y otros que se discutirán en esta revisión.

El tamaño de la molécula por sí solo no es un buen factor predictivo de la RR. Se ha observado que moléculas dentro del mismo rango de PM pueden presentar variaciones drásticas en su $\mathrm{RR}^{102}$. A estas dificultades se suman también aspectos técnicos inherentes a los cambios en las propiedades físicas de la membrana de $100 \mathrm{kDa}$ con respecto a las membranas tradicionales de $20 \mathrm{kDa}$. Una de las preocupaciones más importantes que han surgido en el uso clínico de las nuevas membranas, se refiere a los fenómenos de ultrafiltración por el aumento de permeabilidad de la membrana, con la pérdida consiguiente de fluido hacia el espacio intersticial. Se ha discutido si es o no necesario añadir agentes coloidosmóticos (dextrano o albúmina) al líquido de perfusión, para compensar la pérdida de líquido hacia el tejido del órgano perfundido. Aunque las bases teóricas de esta situación están bien fundamentadas, la evidencia científica es todavía contradictoria.

\section{Mediadores de inflamación cerebral}

Aun cuando el estricto control de la BHE en condiciones normales mantiene al sistema nervioso central protegido de los procesos que inducen una respuesta inflamatoria sistémica, en el caso de un TCEG puede desencadenarse, en cuestión de minutos, una respuesta inflamatoria análoga a la que puede encontrarse en cualquier otro órgano. Esta respuesta está en parte promovida por mediadores proinflamatorios expresados localmente por los astrocitos, por las células microgliales y por las propias neuronas. Estos mediadores inician una cascada de eventos que promueven la disrupción de la BHE, la expresión de moléculas de adhesión, la infiltración celular y una amplificación de la expresión de mediadores proinflamatorios. La neuroinflamación puede tener efectos beneficiosos o por el contrario contribuir al daño secundario y a la muerte neuronal en el TCE, una dualidad cuyos mecanismos e interacciones son muy complejos y no están aún bien perfilados ${ }^{3,9,24,65,66}$. Parte de esta complejidad viene dada por las características de las moléculas involucradas, las citocinas.

Las citocinas son proteínas con un PM relativamente bajo (entre 8-80 kDa), y que se secretan por diferentes tipos de células durante la respuesta inmunitaria. En concentraciones relativamente bajas, las citocinas pueden ejercer acciones directas en las neuronas, e indirectas en las células gliales y en el endotelio capilar. Pueden además afectar parámetros fisiológicos tales como la temperatura o el flujo sanguíneo regional ${ }^{59,60,72}$. Las citocinas, tienen estructuras que pueden ser agrupadas en familias, y en función de esto pueden actuar sobre distintos tipos de receptores. Algunas de estas moléculas comparten un número de características funcionales, como su capacidad de estimular o suprimir la síntesis de otras citocinas, produciendo lo que se conoce como "cascadas". En estas cascadas, varias citocinas actúan como mediadoras unas de otras en una especie de ciclo de retroalimentación. Las CKs tienen también otras propiedades como: 1) pleiotropismo, entendido como la capacidad de actuar sobre varios grupos celulares distintos, 2) redundancia, definida como la capacidad de que 
varias CKs tengan el mismo efecto funcional, 3) sinergia, o la capacidad de potenciar la acción de otras CKs, y 4) antagonismo o su capacidad para inhibir otras citocinas ${ }^{1,30}$. Entre los efectos biológicos inducibles se encuentran la estimulación o inhibición de la proliferación celular, la apoptosis o citotoxicidad, la acción antiviral y el estímulo a la expresión de otras proteinas ${ }^{9,30,66}$. En los TCE, suscitan especial interés aquellas CKs involucradas en la respuesta inflamatoria precoz, debido al potencial beneficio que podría derivarse de su modulación en las etapas más prematuras tras la lesión neurotraumática.

Dada la relevancia de estos mediadores, varios autores han intentado y conseguido recuperar CKs empleando membranas de MD tanto in vitro como in vivo. Entre las citocinas que se han recuperado mediante el uso de MD en diferentes tejidos están la IL1 $\beta^{7,35,46,52,62,96,102,107}$, la IL6 6-8,46,6 $2,87,96,102,107,108$, la IL2 $2^{7,8}$, la IL8 ${ }^{62,102}$, la IL10 $0^{8,102}$, y el TNF $\alpha^{6-}$ $8,17,96,102$. Las condiciones en las que se ha conseguido su recuperación varían en función de las características de la membrana utilizada, del líquido de perfusión (con/sin dextrano), de la velocidad de perfusión, del medio empleado para los experimentos in vitro (solución acuosa o geles de agarosa) o del tejido evaluado en experimentos in vivo (subcutáneo, cerebral, u otros).

Un factor común en estos trabajos, es que la RR de las moléculas de interés, aunque varía dependiendo de las condiciones específicas de cada estudio, es mucho más baja que lo que podría predecirse según su PM y el punto de corte de la membrana dializante. Por ejemplo, en el caso del TNF $\alpha$, la RR oscila entre el 1 y 5\% $\%^{7,8,102}$. Esta escasa recuperación, ha fomentado en algunos grupos de investigación la experimentación con métodos vanguardistas, tales como el uso de microesferas con anticuerpos monoclonales específicos en el líquido de perfusión, capaces de acrecentar el transporte por difusión a través de las membranas dializantes ${ }^{6-8,32}$.

\section{Proteínas involucradas en la respuesta inflamatoria cerebral}

El conocimiento previo de la estructura molecular y de las propiedades de las proteínas de interés puede ser útil para predecir o explicar fenómenos relacionados con la $\mathrm{RR}$ de dichas moléculas. La mayoría de las CKs se pueden clasificar en familias con estructuras análogas que actúan sobre receptores estructuralmente similares. Los principales grupos incluyen la familia de la IL-1, la superfamilia de citocinas/hematopoietinas tipo I y II, las quimiocinas, y la superfamilia del $\mathrm{TNF}^{30}$.

A modo de ejemplo, en los siguientes apartados se describen someramente las estructuras de algunas de las moléculas más interesantes en el contexto de la respuesta inflamatoria post-traumática, en concreto de las CKs IL1 $\beta$, IL6, IL8, IL10 y TNF $\alpha$ y de las metaloproteinasas MMP2 y MMP9. Este panel específico de proteínas podría ofrecer una representación global de los procesos neuroinflamatorios que tienen lugar en las horas y días siguientes a la lesión primaria en el TCE.

En la respuesta inflamatoria inicial tras el impacto, la respuesta innata se activa con rapidez y sus principales mediadores parecen ser el TNF $\alpha$ y la IL1 1,11,35,38,82,98. Ambas moléculas son capaces de inducir precozmente la alteración de la permeabilidad de la BHE, el reclutamiento de leucocitos y la estimulación de la producción de otras citocinas $^{11,82}$. Tanto la IL1 $\beta$, la IL6 como el TNF $\alpha$ han sido detectadas en el LCR de pacientes con un TCE grave ${ }^{79}$. La expresión de IL6, por su parte, puede aumentar de forma muy precoz y sus niveles han sido relacionados en diferentes estudios a otras lesiones cerebrales agudas como la hipoxia ${ }^{48,53,54,86}$. Se ha sugerido también que la IL6 tiene propiedades neuroprotectoras ${ }^{86}$, por lo que su perfil temporal en el cerebro lesionado es altamente relevante.

La IL8 por su parte es una quimiocina cuya implicación en el TCE guarda relación con la formación de edema y ruptura de $\mathrm{BHE}^{53,90}$. La IL10, por otro lado, está presuntamente involucrada en el control de la inflamación tras el TCE, y parece existir una relación inversa entre los niveles de IL10 en relación a los de TNF $\alpha^{29}$.

Adicionalmente a las citocinas, las metaloproteasas de matriz (MMPs) son enzimas proteolíticas involucradas en la remodelación de la matriz extracelular. En particular la subfamilia formada por la MMP2 y MMP9, también denominadas gelatinasas, son capaces de degradar los componentes de la membrana basal del endotelio cerebral ${ }^{56,67,7576,85,98}$. En estudios experimentales y clínicos se ha relacionado la sobreexpresión de gelatinasas con el desarrollo de la lesión secundaria en el TCE ${ }^{104}$. Además, la inducción de esta sobreexpresión está regulada por las CKs proinflamatorias ${ }^{39,92,98}$. En estudios preliminares, nuestro grupo ha detectado mediadores de respuesta inflamatoria en homogeneizados de contusiones cerebrales evacuadas quirúrgicamente. En estas lesiones hemos detectado niveles elevados de IL1 $\beta$, IL6, MMP2 y MMP9 en comparación con controles obtenidos de pacientes no traumáticos ${ }^{99}$.

\section{Peso molecular y características estructurales de las proteínas de interés}

Como se ha comentado previamente, la recuperación mediante MD, no sólo de citocinas, sino de polipéptidos y proteínas en general, está limitada por el PM de la molécula, pero también por su estructura tridimensional. La denominada estructura terciaria de una proteína se refiere a la configuración tridimensional que adopta la molécula monomérica al plegarse. Si la proteína en su forma funcional existe en forma de dímeros o trímeros, a esta conformación se la denomina estructura cuaternaria ${ }^{69,101}$. 


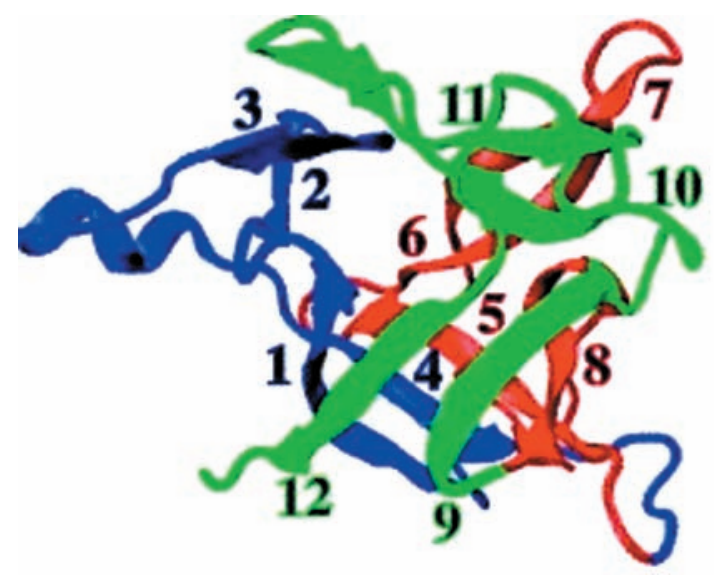

Figura 1. Estructura tri-hoja de la IL1B, con las láminas$\beta$ numeradas del 1 al $12^{37}$ (Protein DataBank ${ }^{15}$ Pdb id 6I1B.pdb).

A continuación describimos las características estructurales básicas de algunas de las moléculas más interesantes en el contexto de la respuesta inflamatoria cerebral posttraumática:

\section{IL1P}

Esta CK pertenece a la familia de la IL1, y se forma a partir de un precursor de $33 \mathrm{kDa}$, escindido por la caspasa1 para generar la forma activa, que tiene un PM de sólo $17 \mathrm{kDa}$. Su actividad es principalmente pro-inflamatoria. Su estructura secundaria consiste de 12 láminas- $\beta$, que se pliegan hasta formar una estructura terciaria de triple hoja $(\text { tri-foil })^{37}$. (Figura 1)

\section{IL8}

Está conformada por un polipéptido de 8-12 kDa, que contiene 2 bucles disulfuro internos ${ }^{80}$. Estructuralmente está formada por una hoja beta y una hélice alfa estabilizada por puentes disulfuro entre sus 4 residuos de cisteína. Es una quimiocina $\alpha$, es decir que tiene una estructura CXC (definida por el espaciamiento de sus residuos de cisteína).

\section{IL6}

Existe en solución como un homodímero, con cada subunidad formando un dominio globular de cuatro hélices alfa de alrededor de 25 aminoacidos $^{89}$ (Figura 2). Su tamaño oscila entre 19-26 kDa. Pertenece a la misma familia estructural que la IL10 y su actividad principal es pro-inflamatoria.

\section{IL10}

Es un homodímero no covalente de $34-40 \mathrm{kDa}$, formado por dos polipéptidos de $17-18 \mathrm{kDa}^{64}$. Tiene un dominio globular formado por 4 hélices alfa largas (Figura 2), y pertenece a la misma familia estructural que la IL6, aunque su

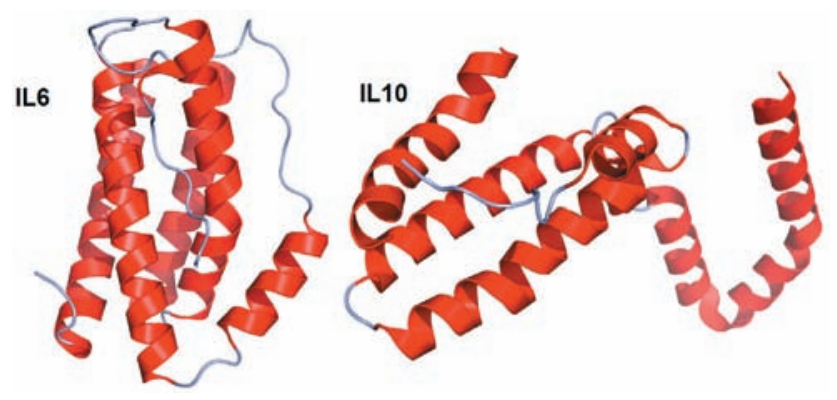

Figura 2. Estructuras cristalinas de los monómeros de las proteínas IL6 $6^{89}$ e IL10 $0^{19,109}$ (cuatro hélices- $\alpha$ ). Imágenes obtenidas del Protein Data Bank ${ }^{15}$, PDB id: 1 ALU y $2 \mathrm{H} 24$ respectivamente.

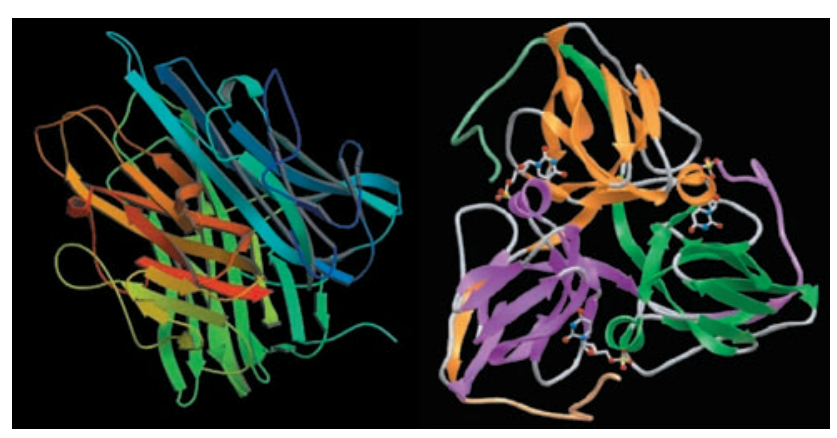

Figura 3. Estructura tridimensional del trimero de TNF $\alpha$. Imágenes obtenidas del Protein Data Bank ${ }^{15}, P D B$ id: 1 thf $f^{33}$.

actividad es principalmente anti-inflamatoria.

\section{TNFa}

El TNF $\alpha$ se sintetiza como un precursor de $26 \mathrm{kDa}$ anclado a la membrana celular, que al ser liberado produce fragmentos de $17 \mathrm{kDa}$ formados por láminas beta. Tres de estas estructuras monoméricas se polimerizan en un homotrímero de $51 \mathrm{kDa}$, conformando la estructura cuaternaria del TNF en su forma circulante ${ }^{33,57}$ (Figura 3). Su actividad es pro-inflamatoria.

\section{Las gelatinasas}

Son una familia de proteasas dependientes de zinc, responsables de la remodelación de la matriz extracelular. Contienen en su estructura común un pro-péptido señal de 80 aminoácidos $^{68}$, un dominio catalítico (100 aminoácidos) $\mathrm{y}$, en la región C-terminal, un dominio de unión a la hemopexina de 210 aminoácidos ${ }^{68}$. En esta familia se incluyen la MMP2 y la MMP9 (Figura 4).

\section{MMP2}

Denominada también gelatinasa $\mathrm{A}$, tiene un PM de $72 \mathrm{kDa}$ en la forma inactiva y de $66 \mathrm{kDa}$ en su forma $\operatorname{activa}^{23,91}$. 


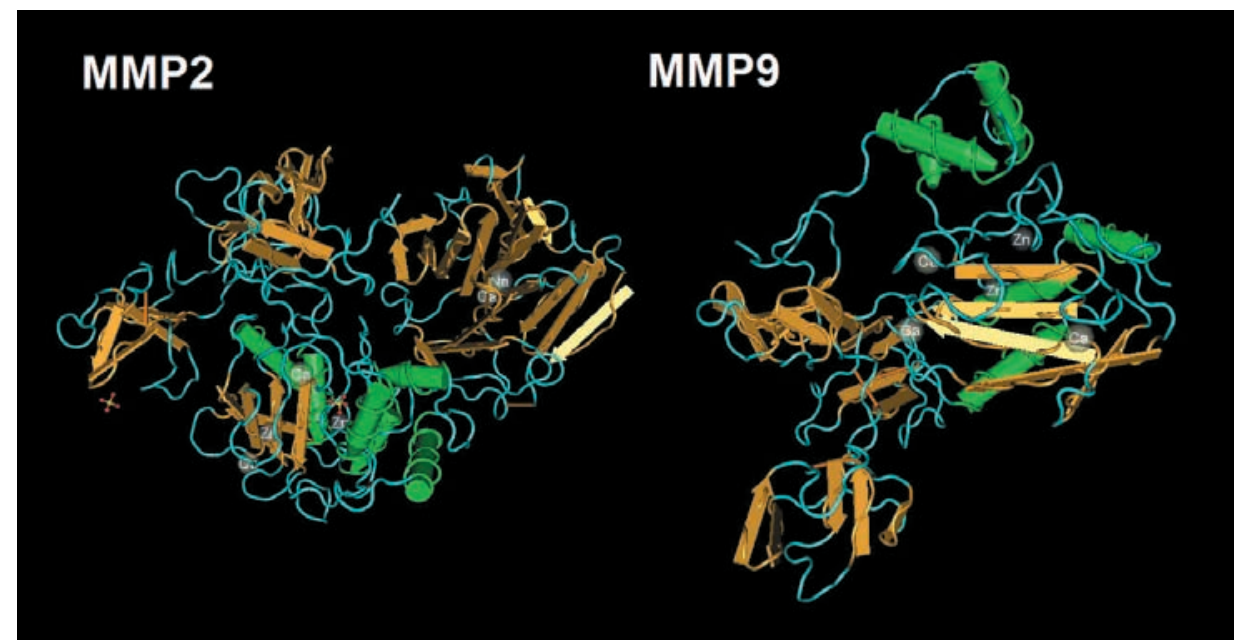

Figura 4. Estructuras tridimensionales de las gelatinasas MMP2 y MMP9. Imágenes obtenidas del Molecular Modeling DataBank ${ }^{25,106:}$ MMP2: mmdbId: 10832; MMP9: mmdbId:19924.

\section{MMP9}

Conocida como gelatinasa $\mathrm{B}$, su peso molecular en su forma inactiva es de $92 \mathrm{kDa}$ y de $83 \mathrm{kDa}$ en su forma $\operatorname{activa}^{23,91}$.

Las proteínas aquí seleccionadas tienen un PM que permite su potencial detección por MD de alta resolución en base al cut-off nominal de las membranas de $100 \mathrm{kDa}$. Además, están involucradas en un abanico de funciones de gran relevancia durante la fase aguda de la lesión cerebral post-traumática, conformando así un panel idóneo para su evaluación en experimentos de RR.

\section{Microdiálisis de alta resolución: aspectos técnicos y metodológicos}

La técnica de monitorización por microdiálisis se basa en la implantación en el tejido de interés, de un catéter de doble luz con una membrana semipermeable en su extremo

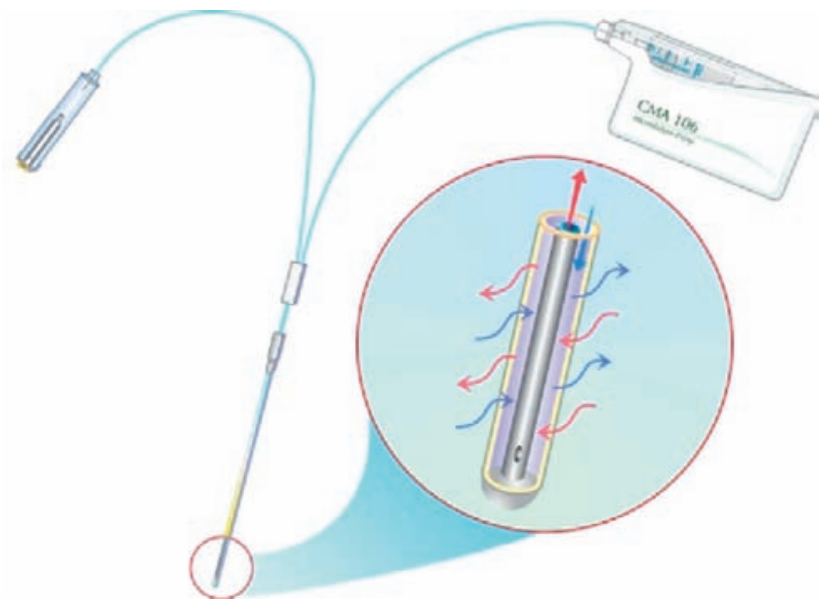

Figura 5. Catéter de microdiálisis mostrando en su punta la membrana semipermeable donde se realiza el intercambio de solutos. Imagen cedida, por cortesía de CMA Microdialysis AB, Solna, Suecia. distal (ubicado en el tejido a estudiar). Este catéter se perfunde con un líquido similar en composición al líquido intersticial del tejido específico en el cual se implanta. Por difusión pasiva y a favor de gradiente, las moléculas de bajo peso molecular atraviesan la membrana dializante y pasan al microdializado, donde su concentración final depende principalmente de varios factores: 1) de la velocidad de perfusión, 2) del calibre de los poros en la membrana, 3) de la temperatura y 4) de las características estructurales de la molécula. El dializado obtenido se puede analizar mediante un sistema enzimático comercial a la cabecera del paciente, que permite medir los niveles relativos de pequeños analitos como la glucosa, el lactato, el piruvato, el glutamato, la urea o el glicerol. A posteriori y mediante técnicas de laboratorio adecuadas a cada analito, pueden determinarse los niveles de otras moléculas de mayor tamaño o complejidad.

\section{Fundamentos de la microdiálisis}

La MD permite examinar, de una forma mínimamente invasiva, la composición molecular del espacio intersticial del tejido de interés. Para ello se inserta un catéter específico en el tejido a estudiar. Este catéter está compuesto de dos tubos concéntricos de diámetro muy fino y en su parte más distal contiene una membrana permeable al agua y a los solutos por debajo del tamaño del cutoff de la membrana. En su extremo proximal, y a través del "tubo de entrada", el catéter se conecta a una microbomba de perfusión, que mantiene un flujo a una velocidad constante dirigido al extremo distal del catéter. Cuando el líquido de perfusión infundido por la bomba, llega a la punta del catéter, entra en contacto con la membrana semi-permeable, y se produce un intercambio de analitos por difusión simple a través de la misma, siguiendo el gradiente de concentración. Las moléculas que atraviesan la membrana y pasan al líquido de perfusión, son arrastradas con el flujo y conducidas hacia el punto de salida del catéter, para ser recogidas en un dis- 
positivo específico al que denominamos microvial (Figura 5). El dializado obtenido no es una muestra exacta, sino un reflejo de las sustancias presentes en el líquido intersticial. Por este motivo es importante conocer los porcentajes de RR para cada analito, y así calibrar los resultados con respecto al medio in vivo. Cuando los analitos son moléculas pequeñas éstas pasarán la membrana con relativa facilidad, pero en el caso de moléculas de mayor tamaño o complejidad estructural el cálculo de la recuperación es mucho más complicado, como se explicará más adelante.

\section{Conceptos básicos sobre difusión}

El intercambio de solutos que tiene lugar durante la microdiálisis está regido por procesos de transporte pasivo por difusión entre las dos fases separadas por la membrana. Este intercambio se expresa matemáticamente mediante la Ley de Fick ${ }^{10}$. Este principio expresa de forma matemática que el flujo neto de materia transportada (J), es igual a una propiedad física, la difusividad (D), multiplicada por un gradiente, en este caso de concentración, según la fórmula expresada en la Ecuación 1:

$$
\mathrm{J}=-\mathrm{D} \frac{\delta \mathrm{c}}{\delta \mathrm{x}}
$$

(Ecuación 1)

En esta ecuación $\delta c$ representa la diferencia de concentración a ambos lados de la membrana y $\delta \mathrm{x}$ la distancia a atravesar por la molécula (longitud), en este caso equivalente al grosor de la membrana dializante. La viscosidad del medio y el tamaño de las partículas también afectarán al coeficiente de difusión (D), de acuerdo a la relación de Stokes-Einstein ${ }^{10}$. Para moléculas biológicas los coeficientes de difusión se encuentran normalmente en el rango de $\operatorname{los} 10^{-11}-10^{-10} \mathrm{~m}^{2} / \mathrm{s}^{10}$.

\section{Recuperación relativa de las proteínas}

Para entender los procesos que intervienen y afectan a la difusión de las proteínas a través de membranas de microdiálisis, varios autores han realizado estudios matemáticos y experimentales, para intentar formular ecuaciones teóricas que permitan predecir los resultados in vivo a partir de resultados de experimentos de recuperación in vitro ${ }^{4,20,21,26,55}$.

La microdiálisis fue diseñada para la recuperación de pequeñas moléculas, como metabolitos y neurotransmisores de bajo peso molecular. La efectividad de la microdiálisis para la recuperación de este tipo de moléculas en el tejido cerebral está bien documentada tanto en el ámbito clínico como experimental ${ }^{2,12,16,36,43,50,97}$. Sin embargo, la situación no es la misma para otras moléculas de mayor PM y complejidad estructural. Antes de explicar las dificultades concernientes a este tipo de moléculas, es necesario introducir los conceptos básicos de recuperación, que derivan a su vez de la fórmula de eficiencia de extracción (extraction efficiency) o EE (Ecuación 2).

$$
\mathrm{EE}=\frac{(\mathrm{Cd}-\mathrm{Ci})}{(\mathrm{Ce}-\mathrm{Ci})} \quad(\text { Ecuación } 2)
$$

En esta ecuación, Cd, Ci y Ce representan las concentraciones del analito de interés en el dializado, en el líquido de perfusión y en el medio externo a analizar respectivamente. Cuando el analito no está presente en el líquido de perfusión $(\mathrm{Ci}=0)$, esta ecuación se simplifica. Bajo estas circunstancias, la RR se expresa como un porcentaje ${ }^{21}$ (Ecuación 3):

$$
\mathrm{RR}=\frac{\mathrm{Cd}}{\mathrm{Ce}} \times 100 \quad \text { (Ecuación 3) }
$$

La RR es a su vez dependiente de diversos parámetros inherentes a las propiedades del medio, a las de la membrana y a las del líquido de perfusión, así como a la velocidad de infusión de este último. Estos parámetros han sido considerados en un modelo matemático propuesto por Bungay $^{21}$ (Ecuación 4), en el que se engloban las resistencias al transporte de masa de los elementos involucrados:

$$
R R=1-\exp \left\{-\frac{1}{Q d(R d+R m+R e}\right\} \text { (Ecuación 4) }
$$

Donde Qd es la velocidad de flujo del líquido de perfusión y $\mathrm{Rd}, \mathrm{Rm}$ y Re representan las resistencias al transporte de masa en el dializado (el líquido de perfusión), la membrana y el medio externo a la membrana respectivamente. Esta ecuación ha sido posteriormente ampliada ${ }^{22,105}$, para tener en cuenta otros parámetros de resistencia que pueden ser relevantes durante la microdiálisis in vivo, tales como el concepto de bioplaca (por deposición y adhesión de componentes biológicos a la membrana, biofouling layer), la capa correspondiente al tejido traumático alrededor del catéter (trauma layer) y también la resistencia inherente al tejido normal ${ }^{22,93}$ (Figura 6).

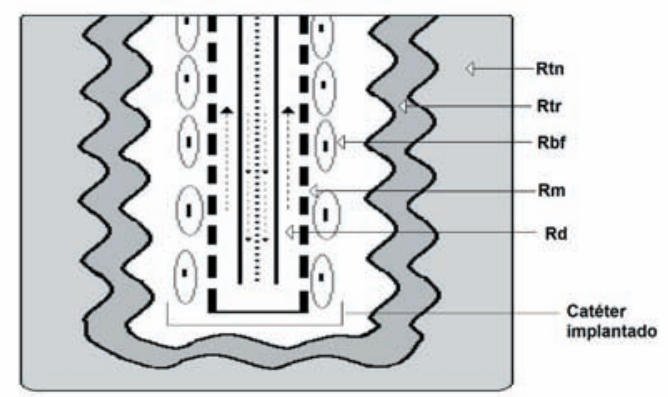

Figura 6: Diagrama que identifica gráficamente los términos de resistencia al transporte de masa en la ecuación modificada de $R R^{103}$. Los términos están representados por Rd (dializado), Rm (membrana), Rbf (bioplaca), Rtr (trauma) y Rtn (tejido normal). 
En el caso de recuperación de proteínas, algunos autores añaden al término correspondiente a la membrana un factor adicional de resistencia correspondiente a la capa de proteínas que puede potencialmente adherirse a la membrana de forma no específica. Este factor se denomina el "factor Andrade", basado en los trabajos de cuantificación de las interacciones de proteínas con superficies realizados por Joseph Andrade ${ }^{5,88}$. Aún cuando es necesario tener en consideración estos parámetros externos al analizar la información obtenida de experimentos in vivo, son las resistencias combinadas correspondientes al dializado y la membrana, $\mathrm{Rd}$ y Rm las que se obtienen con mayor precisión en experimentos in vitro ${ }^{105}$.

Según la definición de Bungay ${ }^{21}$ estos dos términos ( $\mathrm{Rm}$ y Rd) se definen como:

$$
\begin{aligned}
& \mathrm{Rd}=\frac{13(\mathrm{ri}-\mathrm{r} \alpha)}{70 \pi \mathrm{Lri} \mathrm{Dd}} \quad(\text { Ecuación } 5) \\
& \mathrm{Rm}=\frac{\mathrm{In}(\mathrm{re} / \mathrm{ri})}{2 \pi \mathrm{L} \mathrm{Dm} \Phi \mathrm{m}} \quad(\text { Ecuación } 6)
\end{aligned}
$$

Donde re y ri son los radios externo e interno de la membrana, r $\alpha$ es el radio de la cánula interior del catéter, L es la longitud de la membrana, Dd y Dm son los coeficientes de difusión del soluto determinado en el dializado y en la membrana, y $\Phi \mathrm{m}$ es la fracción volumétrica de la membrana que es accesible por el solvente.

Todos los términos en esta ecuación dependen de las propiedades físicas del catéter y son constantes para cada catéter, excepto los términos Dd y Dm, que son específicos para cada molécula. Para una proteína globular, el coeficiente de difusión acuoso, equivalente a Dd, puede ser estimado teóricamente utilizando la ecuación de StokesEinstein ${ }^{10}$. Sin embargo, esta estimación solo es válida para moléculas esféricas en su conformación tridimensional. Para macromoléculas de otras características, predecir el coeficiente de difusión acuosa es un proceso más complejo, aunque factible de obtener experimentalmente ${ }^{84}$.

Por otro lado, el coeficiente de difusión inherente a la membrana, Dm, depende de otros factores tales como $\lambda$, definido como la proporción entre el radio hidrodinámico de la molécula y el radio del poro, la porosidad de la membrana (equivalente a $\Phi \mathrm{m}$ ), el grosor de la membrana y su permeabilidad hidráulica ${ }^{105}$, además de interacciones no específicas entre las moléculas y la membrana.

El radio hidrodinámico, o radio de Stokes-Einstein, está definido como el radio de una esfera rígida hipotética cuya velocidad de difusión es la misma que la media de las velocidades de difusión de sus diferentes orientaciones espaciales. Este radio se calcula a partir de datos de coeficientes de difusión obtenidos mediante técnicas de difusión dinámica de luz (Dynamic Light Scattering, DLS). En la práctica, es infrecuente que las macromoléculas sean

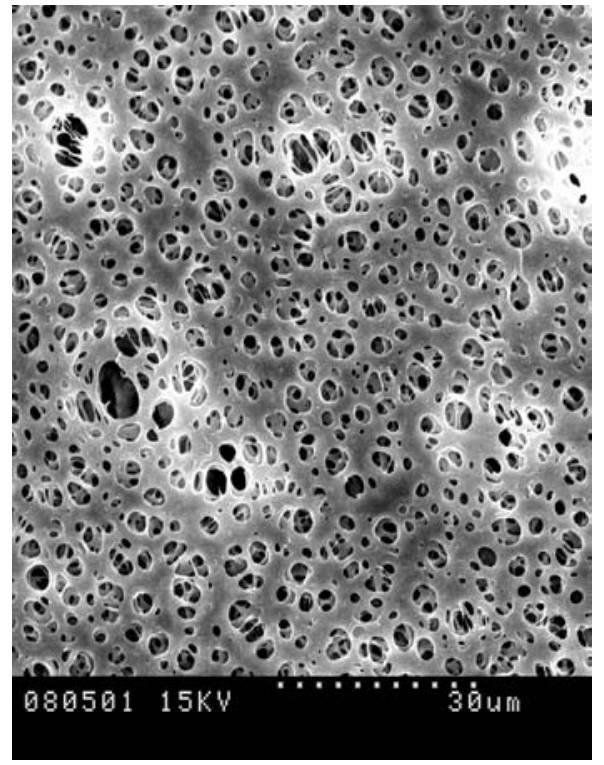

2009; 20: 433-448

Figura 7. Imagen de microscopía electrónica de barrido (SEM) de la superficie externa de una membranade microdiálisis de polietersulfona.

rígidas y esféricas, sino que son especies dinámicas, que pueden interactuar con el solvente en el que están disueltas. Por este motivo, el radio calculado es indicativo del tamaño aparente tomando en cuenta los procesos de atracción y asociación con moléculas del solvente, y de allí su nombre, "radio hidrodinámico".

\section{Características de la membrana microdializante}

El punto de corte (cut-off) es un término utilizado para describir el tamaño de poro de las membranas de microdiálisis, cuya definición está basada en la capacidad de la membrana de restringir el paso del $80 \%$ de las moléculas del peso molecular expresado en Daltons. Así por ejemplo, un cut-off de $20 \mathrm{kDa}$ no permitiría el paso del $80 \%$ de las moléculas presentes en el medio perfundido con un PM de $20 \mathrm{kDa}$. Sin embargo, debido a que la distribución y el tamaño de los poros no es homogénea, un pequeño porcentaje de moléculas de peso molecular superior al cut-off pueden recogerse en el microdializado, aunque con una RR impredecible. Es importante destacar que la definición de cut-off toma en consideración los pesos moleculares, pero no así la estructura tridimensional de las moléculas. En el caso de las proteínas, este es un factor a tener en cuenta, puesto que si el radio hidrodinámico de la molécula es mucho mayor que el poro, esta molécula no pasará a través de los poros de la membrana, aún cuando su PM sea menor al cut-off nominal.

\section{Descripción de la membrana de microdiálisis}

La membrana de los catéteres de $100 \mathrm{kDa}$, tiene una estructura de poros heterogéneos, con una capa exterior de poros de un diámetro aproximado $1000 \mathrm{~nm}$ (Figura 7), que 
sirve como soporte a una capa interna formada por una red de poros de menor tamaño ${ }^{105}$.

El material del que esta compuesto la membrana de los catéteres de microdiálisis de $100 \mathrm{kDa}$ es la polietersulfona, cuya composición química previene la adsorción de materia biológica potencialmente adherente. Sin embargo, esto no garantiza que no ocurran interacciones entre proteínas y la membrana dializante ${ }^{95}$, dado que las proteínas poseen características muy heterogéneas no sólo en cuanto a la distribución de sus cargas, sino también en su hidrofobicidad, su conformación tridimensional, rigidez y tamaño. Los fenómenos de "taponamiento" por interacciones entre proteínas y la membrana se pueden clasificar en 3 tipos: 1) deposición de partículas, quedando las proteínas atrapadas dentro de los poros de la membrana, 2) formación de una película o "biogel" en la superficie de la membrana, y 3) adsorción de las partículas, en la superficie de la membrana, o en las paredes interiores de la estructura porosa $^{95}$. Todas estas interacciones inhiben o disminuyen el transporte de solutos y afectan de manera importante su recuperación.

La implantación in vivo de un catéter cerebral de microdiálisis provoca pequeñas lesiones en el tejido donde se implanta ${ }^{27}$, y su implantación en el encéfalo puede dar lugar a la formación de gliosis reactiva alrededor del catéter. Este fenómeno puede actuar como una barrera a la difusión de las sustancias del líquido intersticial. Esta acumulación de material podría disminuir la recuperación de moléculas de interés cuando la microdiálisis se realiza por periodos de tiempo prolongados. Aunque la recuperación de metabolitos y moléculas de pequeño tamaño parece no verse afectada hasta 11 días tras la implantación ${ }^{42}$, no está muy claro que el caso sea el mismo para moléculas de mayor tamaño.

Rosenbloom $^{78}$ evaluó la recuperación de proteínas usando membranas de $100 \mathrm{kDa}$, encontrando que dicha recuperación disminuye a lo largo de los días. En un estudio reciente de Wang et al ${ }^{103}$ se comparó utilizando microscopía electrónica la superficie de membranas de microdiálisis de $100 \mathrm{kDa}$ de catéteres nuevos extraídos durante la fase aguda, con la de catéteres implantados durante 3 o 7 días. Las imágenes mostraron un menor número y tamaño de los poros externos en las membranas implantadas durante más tiempo, sin embargo la resolución de la técnica empleada no permite determinar el estado de los poros internos de la membrana. En el mismo estudio, se comparó la recuperación de IL6 a los 3 y a los 7 días tras la implantación. Aún cuando la recuperación in vivo fue significativamente menor para los catéteres implantados durante tres y siete días que para los catéteres nuevos, una posterior calibración in vitro no demostró diferencias significativas entre las RR de los diferentes catéteres.

\section{El líquido de perfusión y la ultrafiltración}

Para la perfusión de los catéteres de microdiálisis cerebral convencionales se utiliza una solución isotónica estéril, de composición análoga al LCR y con una concentración fisiológica de cloruros de sodio, potasio, magnesio y calcio. Cuando se comercializaron por primera vez los catéteres de microdiálisis de alta resolución (100 kDa), una serie de autores sugirieron que debido al mayor tamaño de los poros, una proporción importante del líquido de perfusión se perdía por ultrafiltración hacia el tejido, y por tanto existía una disminución importante en la recuperación volumétrica $^{73,74,77,78,87}$.

Para explicar el fenómeno de ultrafiltración se considera que el catéter de microdiálisis es análogo a un capilar sanguíneo. Las moléculas de alto peso molecular no atraviesan con facilidad la membrana capilar, y por lo tanto generan una presión oncótica. La diferencia en la concentración de proteínas (principalmente albúmina) entre el plasma y el espacio intersticial, genera una presión conocida como presión coloidosmótica u oncótica. La fuerza neta de movimiento de flujo (FMF), viene entonces dada por la siguiente fórmula:

$$
\mathrm{FMF}=(\mathrm{Pc}-\mathrm{Pi})-\sigma(\pi \mathrm{c}-\pi \mathrm{i}) \quad(\text { Ecuación } 7)
$$

Donde Pc y Pi representan las presiones hidrostáticas del capilar y del intersticio, $\pi \mathrm{c}$ y $\pi \mathrm{i}$ representan las respectivas presiones oncóticas. $\sigma$ es el coeficiente de reflexión. El flujo neto, Jv, depende tanto de la FMF, como de la superficie en la que ocurre el intercambio y de la permeabilidad de la membrana, expresada como la constante de filtración $\mathrm{Kf}$, que depende de las propiedades físicas de la membrana (tamaño y número de poros).

$$
\begin{gathered}
\mathrm{JV}=\mathrm{K}_{\mathrm{f}} \text { A FMF } \quad(\text { Ecuación 8) } \\
\mathrm{JV}=\mathrm{K}_{\mathrm{f}} \mathrm{A}[(\mathrm{Pc}-\mathrm{Pi})-\sigma(\pi \mathrm{c}-\pi \mathrm{i})] \quad(\text { Ecuación 9) }
\end{gathered}
$$

A partir de esta fórmula es fácil deducir que si FMF es diferente a 0 , una $\mathrm{Kf}$ mayor repercutirá en un mayor flujo neto. Esta ecuación es conocida como la ecuación de Starling ${ }^{40}$ quien formuló esta teoría en 1896 para modelar el papel que ejercen las fuerzas hidrostáticas y oncóticas en los movimientos de flujo por filtración a través de membranas capilares ${ }^{40}$. Según la ley de Starling, para que el intercambio transcapilar esté en equilibrio, la suma de las presiones hidrostáticas y coloidosmóticas a ambos lados de la membrana debe estar en equilibrio $(\mathrm{FMF}=0)^{40}$. Si extrapolamos esta ecuación a un catéter de microdiálisis, encontramos que la fuerza correspondiente a la presión coloidosmótica del plasma no está presente en el líquido de perfusión que circula a través del catéter, ya que éste 


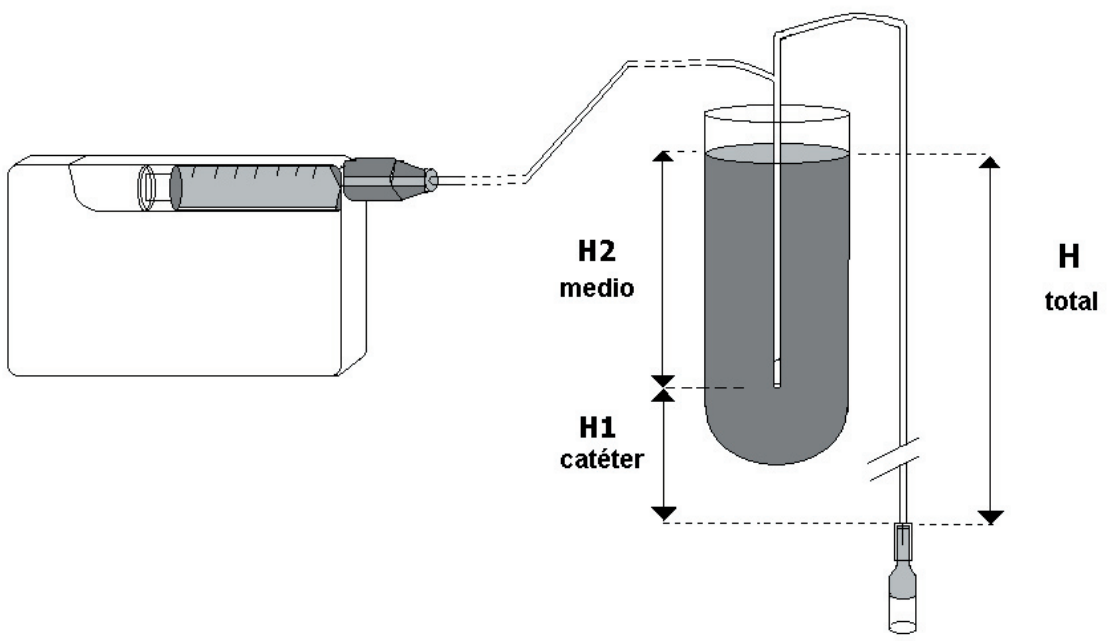

Figura 8. Representación de los dos componentes de presión hidrostática, H1(catéter) y H2(medio), que actúan sobre la membrana de microdiálisis en los experimentos in vitro. Dibujo original. no contiene proteínas. En esta situación, se produce un desequilibrio que da lugar a un flujo neto del líquido de perfusión hacia el espacio intersticial.

\section{Soluciones al problema de la ultrafiltración}

En las membranas de $100 \mathrm{kDa}$ el calibre de los poros es mayor y la resistencia al flujo es menor, por lo que los episodios de ultrafiltración por diferencias entre presiones hidrostáticas/oncóticas, podrían potencialmente afectar la recuperación volumétrica, generándose un flujo neto de líquido de perfusión hacia el tejido perfundido. Entre los mecanismos que han sido utilizados tanto in vitro como in vivo para intentar equilibrar esta pérdida, se encuentra el sistema denominado push-pull, en el cual la presión hidrostática ejercida por el fluido circulante propulsado por la bomba se compensa aplicando una presión negativa (succión) mediante una bomba de extracción en el tubo de salida de igual magnitud que la presión ejercida por la bomba de perfusión ${ }^{87}$.

No obstante, el método hasta ahora más utilizado, y que reproduce la fisiología normal con mayor fidelidad, consiste en la adición de agentes coloidosmóticos como la albúmina ${ }^{96}$ o el dextrano ${ }^{31,41,45,47,73,74,77,78,87,102}$ al líquido de perfusión. Esta última opción ha sido postulada como una de las soluciones mas adecuadas para superar la dificultad técnica de la ultrafiltración y lograr obtener el volumen de muestra deseado. La mayoría de grupos han optado por el dextrano 60/70. De hecho, CMA Microdialysis, fabricante de los catéteres de $100 \mathrm{kDa}$ disponibles comercialmente, recomienda añadir $30 \mathrm{~g} / \mathrm{L}$ de dextrano 60 en el líquido de perfusión ${ }^{28}$. Sin embargo, este líquido de perfusión con dextrano, aún cuando está comercialmente disponible en países Escandinavos, no cuenta con la aprobación sanitaria de la CE para su distribución en el resto de Europa. Por consiguiente, los estudios en los que se ha utilizado dextrano en el líquido de perfusión provienen casi exclusivamente de grupos Escandinavos ${ }^{41,45,47,73,74,87,102}$.
En la microdiálisis cerebral, un estudio de Hutchinson comparó la recuperación volumétrica de los catéteres de 20 y $100 \mathrm{kDa}$ y demostró que, a pesar de no añadir dextrano, no existían diferencias en el volumen del dializado ${ }^{51}$. Ante esta evidencia, aparentemente contradictoria, la necesidad de añadir dextrano u otros agentes coloides al líquido de perfusión permanece aún sin clarificar. Debe considerarse también que cualquier método utilizado para aumentar el volumen del microdializado debe buscar el equilibrio entre el volumen infundido y el volumen recogido, pues de otra forma se aumentaría el volumen a expensas de extraer agua del medio, lo cual diluiría más la muestra recogida, alterando los cálculos de recuperación. Este efecto ya fue observado en las concentraciones de proteínas in vitro obtenidas por Rosenbloom ${ }^{78}$ al comparar liquido de perfusión con y sin dextrano. El dextrano aumentó el volumen de la muestra pero no la cantidad total de proteína en el dializado, ya que simplemente la muestra se encontraba más diluida.

Una forma de similar efectividad para controlar los fenómenos de ultafiltración es manipular la presión hidrostática del interior del catéter modificando la posición del microvial de recogida. La idea es crear un "efecto sifón" (presión hidrostática negativa) que compense la presión coloidosmótica entre el líquido de perfusión y la solución de proteínas que se quiere analizar. Esto se consigue estableciendo una diferencia hidrostática conocida, mediante la colocación del microvial a una distancia determinada por debajo de la punta del catéter. Este procedimiento ha sido utilizado previamente en experimentos in vitro ${ }^{78}$. In vitro, el líquido en el que está inmerso el catéter ejerce también una presión hidrostática sobre el catéter, proporcional a la profundidad a la que está inmerso el catéter. Según la ley de Starling, esta presión hidrostática en el exterior de la membrana promueve el flujo de líquido hacia el interior del catéter. Cuando la posición del microvial es inferior al nivel de la punta del catéter, la presión hidrostática generada es negativa, y se promueve entonces el movimiento de flujo hacia el interior del catéter. 
La presión hidrostática total será pues proporcional a la distancia entre la superficie de la solución en que está inmerso el catéter, y la posición del microvial por debajo de dicha superficie, como muestra la Figura 8.

\section{Factores que afectan la recuperación relativa}

Los experimentos in vitro no pueden proporcionar una información exacta sobre la recuperación in vivo, pero sí pueden aportar una idea aproximada del rango máximo de RR que se puede obtener cuando los factores limitantes dependen sólo de las interacciones entre la membrana y las moléculas de interés. Aun así, para que esta información sea de utilidad para el análisis de la microdiálisis in vivo, es necesario adaptar en lo posible las variables involucradas de manera que se aproximen a las condiciones encontradas in vivo, y en particular a las condiciones y características particulares utilizadas en la monitorización del paciente neurocrítico. Entre estos factores se encuentran:

\section{La velocidad de perfusión}

La velocidad de perfusión, viene predeterminada por la microbomba y es indirectamente proporcional a la RR. Este es uno de los factores más importantes ya que una menor velocidad de perfusión permite que el intercambio a través de la membrana se aproxime más a una situación de equilibrio. Las velocidades de perfusión excesivamente lentas, aun cuando conllevan una mejor RR, tienen implicaciones negativas en lo que respecta a resolución temporal y al volumen del microdializado ${ }^{71}$. La velocidad de perfusión de $0,30 \mu \mathrm{l} / \mathrm{min}$ empleada en nuestro centro permite realizar colecciones horarias de $18 \mu$ l. Una importante acotación es que debido a que el volumen de dializado necesario para realizar análisis de proteómica generalmente ronda los $100 \mu \mathrm{l}$, no es posible obtener datos horarios como en la microdiálisis clásica, sino que es necesario combinar muestras cada 6-8 horas, lo cual disminuye la resolución temporal de la técnica.

\section{Los coeficientes de difusión}

Los coeficientes de difusión acuosa de las moléculas varían en función de su peso molecular y de la estructura y el radio hidrodinámico de cada molécula. El coeficiente de difusión es específico para cada molécula en cada medio determinado, por lo que será diferente en experimentos in vitro o in vivo. En tejidos biológicos, también cobra importancia la tortuosidad del espacio intersticial, que representa el grado de obstrucción a la difusión generado por obstáculos físicos en tejidos de estructura no homogénea $^{49,81}$.

\section{La temperatura}

La temperatura a que se realiza la microdiálisis influye directamente sobre la difusión, ya que afecta a los coeficientes de difusividad tal como indica la relación de Stokes-Einstein ya mencionada. Lindefers determinó que la recuperación de sacarosa in vitro era $40 \%$ más alta a $37^{\circ} \mathrm{C}$ que a $20^{\circ} \mathrm{C}^{55}$. En general los coeficientes de difusión aumentan entre $1-2 \%$ por ${ }^{\circ} \mathrm{C}^{13}$.

\section{Longitud de la membrana}

La RR es proporcional a la superficie de la membrana. Los catéteres de microdiálisis de $100 \mathrm{kDa}$ comercializados para uso clínico por CMA Microdialysis (Solna, Suecia) están disponibles con membranas dializantes de 10,20 o $30 \mathrm{~mm}$. En nuestro centro se implantan catéteres de microdiálisis cerebral de $10 \mathrm{~mm}$ de longitud de membrana. $\mathrm{Si}$ bien es cierto que una longitud mayor de la membrana aumenta la recuperación debido a una mayor superficie dializante, las membranas más largas son técnicamente más difíciles de implantar en la zona anatómica diana, se rompen con mayor facilidad y se corre además el riesgo de monitorizar áreas heterogéneas del tejido cerebral.

\section{Líquido de perfusión}

El líquido de perfusión utilizado habitualmente para la microdiálisis cerebral, es una solución isotónica comercializada por CMA Microdialysis (Solna, Suecia), con una concentración de electrolitos similar a la del líquido cefalorraquídeo, cuya composición es la siguiente: $\mathrm{NaCl}$ $147 \mathrm{mmol} / \mathrm{L}, \mathrm{KCl} 2,7 \mathrm{mmol} / \mathrm{L}, \mathrm{CaCl}_{2} 1,2 \mathrm{mmol} /{\mathrm{L} \mathrm{y} \mathrm{MgCl}_{2}}_{2}$ $0,85 \mathrm{mmol} / \mathrm{L}$. Para uso clínico, nuestro centro no utiliza coloides en el líquido de perfusión, aun cuando la propia casa comercial recomienda su utilización para los catéteres de $100 \mathrm{kDa}$.

\section{Tiempo de uso del catéter}

El tiempo de uso del catéter tiene efectos en la RR tanto in vivo como in vitro, siendo mayor la recuperación en las primeras horas tras la implantación hasta alcanzar un estado estacionario ${ }^{13}$. En experimentos in vivo, la lesión provocada por la implantación del catéter puede tener efectos tisulares durante las primeras horas tras la inserción, produciendo pequeñas lesiones hemorrágicas, infiltración de macrófagos, astrogliosis, y afectación de la barrera hematoencefálica posterior a la implantación ${ }^{13,14,27,63}$. Cuando el catéter permanece implantado durante varios días se produce una acumulación de placa alrededor del catéter ${ }^{103}$ que puede disminuir su capacidad de intercambio y por lo tanto su recuperación, particularmente si se intentan recuperar moléculas de PM elevado.

\section{Extrapolación de experimentos in vitro a sistemas in vivo}

Los valores obtenidos en experimentos de RR in vitro pueden aportar valores orientativos de las limitaciones de la 
membrana de microdiálisis para evaluar niveles absolutos de proteínas en un sistema in vivo. Para moléculas como las citocinas, extrapolar resultados in vitro a un sistema in vivo requiere tener en cuenta no sólo factores generales como la tortuosidad del tejido, sino también interacciones entre las proteínas estudiadas y las estructuras y componentes de la matriz extracelular ${ }^{8}$.

Resulta pues muy complicado realizar una aproximación a la RR in vivo basados únicamente en porcentajes de RR in vitro. Por este motivo, se han sugerido varios métodos alternativos para determinar la RR in vivo, tales como el método de Lonnroth o de "no flujo neto" ${ }^{8,93}$. Este método se basa en añadir al líquido de perfusión diferentes concentraciones del analito de interés, para luego determinar, mediante regresión lineal, la concentración real en el medio. Sin embargo, este método tiene importantes limitaciones. Para moléculas como las citocinas, con un rango funcional tan amplio a concentraciones bajas, la determinación de RR en tejido cerebral mediante este método en humanos sería peligrosa y poco ética, con la dificultad metodológica añadida de que la concentración local en el medio debe ser constante durante la duración del experimento.

A pesar de sus limitaciones, el cálculo de la $\mathrm{RR}$ in vitro es útil para determinar las limitaciones de la membrana en relación al paso de proteínas, y como herramienta para discriminar cuales de las proteínas de interés son recuperables con membranas de alta resolución.

\section{Conclusiones}

El estudio de la respuesta neuroinflamatoria cerebral tras el TCE podría verse enriquecido mediante la posibilidad de valorar los niveles de marcadores proteicos en el tejido lesionado. La microdiálisis de alta resolución ofrece esta posibilidad, pero existen limitaciones importantes que deben de ser consideradas y que pueden restringir la recuperación de estas moléculas, y por lo tanto la utilidad de la microdiálisis. Antes de comenzar cualquier proyecto de investigación que pretenda estudiar proteínas mediante microdiálisis, es necesario analizar a fondo dichas limitaciones y realizar estudios in vitro previos para conocer la RR y poder así aproximar la validez a los resultados obtenidos en los pacientes.

\section{Agradecimientos}

Este trabajo ha sido financiado a partir de la beca del Fondo de Investigación Sanitaria de la Seguridad Social (expediente PI051092) concedida al Dr. J. Sahuquillo.

\section{Bibliografía}

1. Abbas, A.K., Lichtman, A.H.: Citocinas, Immunología Celular y Molecular, ed $5^{\text {th }}$. Madrid: Elsevier España,S.A., 2004, pp 243-274.

2. Alessandri, B., Doppenberg, E.M., Bullock, M.R.R., et al,: Glucose and metabolism after severe human head injury: influence of excitatory neurotransmitters and injury type. Acta Neurochir Suppl (Wien) 1999; 75: 21-24.

3. Allan, S.M., Rothwell, N.J.: Cytokines and acute neurodegeneration. Nat.Rev.Neurosci.2001; 2: 734-744.

4. Amberg, G., Lindefors, N.: Intracerebral microdialysis: II. Mathematical studies of diffusion kinetics. J. Pharmacol. Methods 1989; 22: 157-183.

5. Andrade, J.D., Hlady, V.: Vroman effects, techniques, and philosophies. J. Biomater. Sci. Polym. Ed 1991; 2: 161172.

6. Ao, X., Rotundo, R.F., Loegering, D.J., et al.: In vivo microdialysis sampling of cytokines produced in mice given bacterial lipopolysaccharide. J. Microbiol. Methods 2005; 62: 327-336.

7. Ao, X., Sellati, T.J., Stenken, J.A.: Enhanced microdialysis relative recovery of inflammatory cytokines using antibody-coated microspheres analyzed by flow cytometry. Anal. Chem. 2004; 76: 3777-3784.

8. Ao, X., Stenken, J.A.: Microdialysis sampling of cytokines. Methods 2006; 38: 331-341.

9. Arvin, B., Neville, L.F., Barone, F.C., et al.: The role of inflammation and cytokines in brain injury. Neurosci. Biobehav. Rev 1996; 20: 445-452.

10. Atkins, P.W.: Molecules in motion, Physical Chemistry, ed $5^{\text {th }}$. Oxford: Oxford University Press, 1994, pp 817-860.

11. Basu, A., Krady, J.K., Levison, S.W.: Interleukin-1: a master regulator of neuroinflammation. J. Neurosci. Res. 2004; 78: 151-156.

12. Bellander, B.M., Cantais, E., Enblad, P.,. et al.: Consensus meeting on microdialysis in neurointensive care. Intensive Care Med 2004; 2166-2169.

13. Benveniste, H.: Brain microdialysis. J Neurochem 1989; 1667-1679.

14. Benveniste, H., Hansen, A.J., Ottosen, N.S.: Determination of brain interstitial concentrations by microdialysis. $\mathrm{J}$ Neurochem 1989; 52: 1741-1750.

15. Berman, H.M., Westbrook, J., Feng, Z., et al.: The Protein Data Bank. Nucleic Acids Res. 2000; 28: 235-242.

16. Bourne, J.A.: Intracerebral microdialysis: 30 years as a tool for the neuroscientist. Clin. Exp. Pharmacol. Physiol 2003; 30: 16-24.

17. Brown, S.A., Mayberry, A.J., Mathy, J.A., et al.: The effect of muscle flap transposition to the fracture site on TNFalpha levels during fracture healing. Plast. Reconstr. Surg. 2000; 105: 991-998.

18. Brunner, M., Langer, O.: Microdialysis versus other 
techniques for the clinical assessment of in vivo tissue drug distribution. AAPS.J.2006; 8: E263-E271.

19. Bullock, R., Nathoo, N.: Injury and cell function, in Reilly P, Bullock R (eds): Head Injury, Pathophysiology and Management, ed $2^{\text {nd }}$. London: Hodder Arnold, 2005, pp 113139.

20. Bungay, P.M., Dedrick, R.L., Fox, E., et al.: Probe calibration in transient microdialysis in vivo. Pharm. Res. 2001; 18: 361-366.

21. Bungay, P.M., Morrison, P.F., Dedrick, R.L.: Steadystate theory for quantitative microdialysis of solutes and water in vivo and in vitro. Life Sci. 1990; 46: 105-119.

22. Bungay, P.M., Newton-Vinson, P., Isele, W., et al.: Microdialysis of dopamine interpreted with quantitative model incorporating probe implantation trauma. J. Neurochem. 2003; 86: 932-946.

23. Chakraborti, S., Mandal, M., Das, S., et al.: Regulation of matrix metalloproteinases: an overview. Mol. Cell Biochem 2003; 253: 269-285.

24. Chavarria, A., Alcocer-Varela, J.: Is damage in central nervous system due to inflammation? Autoimmun. Rev 2004; 3: 251-260.

25. Chen, J., Anderson, J.B., DeWeese-Scott, C., et al.: MMDB: Entrez's 3D-structure database. Nucleic Acids Res. 2003; 31: 474-477.

26. Chen, K.C., Hoistad, M., Kehr, J., et al.: Theory relating in vitro and in vivo microdialysis with one or two probes. J. Neurochem. 2002; 81: 108-121.

27. Clapp-Lilly, K.L., Roberts, R.C., Duffy, L.K., et al.: An ultrastructural analysis of tissue surrounding a microdialysis probe. J. Neurosci. Methods 1999; 90: 129-142.

28. CMA Microdialysis: CMA 71 High Cut-Off Brain Microdialysis Catheter. CMA Microdialysis Product Notes 2006.

29. Csuka, E., Morganti-Kossmann, M.C., Lenzlinger, P.M., et al.: IL-10 levels in cerebrospinal fluid and serum of patients with severe traumatic brain injury: relationship to IL6, TNF-alpha, TGF-beta1 and blood-brain barrier function. J. Neuroimmunol. 1999; 101: 211-221.

30. DeFranco, A.L., Locksley, R.M., Robertson, M.: Immunity, The Immune Response in Infectious and Inflammatory Disease. London: New Science Press Ltd, 2007.

31. Dostalova, I., Pacak, K., Nedvidkova, J.: Application of in vivo microdialysis to measure leptin concentrations in adipose tissue. Int. J. Biol. Macromol. 2003; 32: 205-208.

32. Duo, J., Fletcher, H., Stenken, J.A.: Natural and synthetic affinity agents as microdialysis sampling mass transport enhancers: Current progress and future perspectives. Biosens. Bioelectron. 2006.

33. Eck, M.J., Sprang, S.R.: The structure of tumor necrosis factor-alpha at $2.6 \mathrm{~A}$ resolution. Implications for receptor binding. J. Biol. Chem. 1989; 264: 17595-17605.

34. Engstrom, M., Polito, A., Reinstrup, P., et al.:
Intracerebral microdialysis in severe brain trauma: the importance of catheter location. J. Neurosurg. 2005; 102: 460-469.

35. Fassbender, K., Schneider, S., Bertsch, T., et al.: Temporal profile of release of interleukin-1beta in neurotrauma. Neurosci.,Lett. 2000; 284: 135-138.

36. Goodman, J.C., Valadka, A.B., Gopinath, S.P., et al.: Extracellular lactate and glucose alterations in the brain after head injury measured by microdialysis. Crit Care Med 1999; 27: 1965-1973.

37. Gosavi, S., Chavez, L.L., Jennings, P.A., et al.: Topological frustration and the folding of interleukin-1 beta. J. Mol. Biol. 2006; 357: 986-996.

38. Gosselin, D., Rivest, S.: Role of IL-1 and TNF in the brain: twenty years of progress on a Dr. Jekyll/Mr. Hyde duality of the innate immune system. Brain Behav. Immun. 2007; 21: 281-289.

39. Gottschall, P.E., Yu, X.: Cytokines regulate gelatinase A and B (matrix metalloproteinase 2 and 9) activity in cultured rat astrocytes. J Neurochem1995; 1513-1520.

40. Guyton, A.C., Hall, J.E.: La Microcirculación y el Sistema Linfático: Intercambio de Líquido Capilar, Líquido Intersticial y Líquido Linfático, Tratado de Fisiología Médica, ed 11 $1^{\text {th }}$. Madrid: Elsevier Inc., 2004, pp 181-194.

41. Hamrin, K., Rosdahl, H., Ungerstedt, U., et al.: Microdialysis in human skeletal muscle: effects of adding a colloid to the perfusate. J Appl Physiol 2002; 92: 385-393.

42. Hillered, L.: Neurochemical monitoring of the acutely injured human brain. Scand J Clin Lab Invest 1999; 59: 9-18.

43. Hillered, L., Persson, L.: Microdialysis for neurochemical monitoring of the human brain. Scand. Cardiovasc. J. 2003; 37: 13-17.

44. Hillered, L., Vespa, P.M., Hovda, D.A.: Translational neurochemical research in acute human brain injury: the current status and potential future for cerebral microdialysis. J Neurotrauma 2005; 22: 3-41.

45. Hillman, J., Aneman, O., Anderson, C., et al.: A microdialysis technique for routine measurement of macromolecules in the injured human brain. Neurosurgery 2005; 56 : 1264-1268.

46. Hillman, J., Aneman, O., Persson, M., et al.: Variations in the response of interleukins in neurosurgical intensive care patients monitored using intracerebral microdialysis. J. Neurosurg. 2007; 106: 820-825.

47. Hillman, J., Milos, P., Yu, Z.Q., et al.: Intracerebral microdialysis in neurosurgical intensive care patients utilising catheters with different molecular cut-off (20 and $100 \mathrm{kD})$. Acta Neurochir. (Wien.) 2006; 148: 319-324.

48. Holmin, S., Hojeberg, B.: In situ detection of intracerebral cytokine expression after human brain contusion. Neurosci Lett 2004; 369: 108-114.

49. Hrabe, J., Hrabetova, S., Segeth, K.: A model of effective diffusion and tortuosity in the extracellular space of the brain. Biophys. J. 2004; 87: 1606-1617. 
50. Hutchinson, P.J.: Microdialysis in traumatic brain injury--methodology and pathophysiology. Acta Neurochir. Suppl 2005; 95: 441-445.

51. Hutchinson, P.J., O'Connell, M.T., Nortje, J., et al.: Cerebral microdialysis methodology--evaluation of $20 \mathrm{kDa}$ and $100 \mathrm{kDa}$ catheters. Physiol Meas. 2005; 26: 423-428.

52. Hutchinson, P.J., O'Connell, M.T., Rothwell, N.J., et al.: Inflammation in human brain injury: intracerebral concentrations of IL-1alpha, IL-1beta, and their endogenous inhibitor IL-1ra. J.Neurotrauma 2007; 24: 1545-1557.

53. Kushi, H., Saito, T., Makino, K., et al.: Neuronal damage in pericontusional edema zone. Acta Neurochir. Suppl 2003; 339-342.

54. Lau, L.T., Yu, A.C.: Astrocytes produce and release interleukin-1, interleukin-6, tumor necrosis factor alpha and interferon-gamma following traumatic and metabolic injury. J. Neurotrauma 2001; 18: 351-359.

55. Lindefors, N.,Amberg, G., Ungerstedt, U.: Intracerebral microdialysis: I. Experimental studies of diffusion kinetics. J. Pharmacol. Methods 1989; 22: 141-156.

56. Lo, E.H., Wang, X., Cuzner, M.L.: Extracellular proteolysis in brain injury and inflammation: role for plasminogen activators and matrix metalloproteinases. J Neurosci. Res 2002; 69: 1-9.

57. Locksley, R.M., Killeen, N., Lenardo, M.J.: The TNF and TNF receptor superfamilies: integrating mammalian biology. Cell 2001; 104: 487-501.

58. Lonnroth, P., Jansson, P.A., Smith, U.: A microdialysis method allowing characterization of intercellular water space in humans. Am. J. Physiol 1987; 253: E228-E231.

59. Male, D.: Introducción al sistema immunitario, in Male D, Brostoff J, Roth DB, et al (eds): Immunología, ed 7. Madrid: Elsevier, 2007, pp 3-18.

60. Male, D.: Mecanismos de immunidad innata, in Male D, Brostoff J, Roth DB, et al (eds): Immunología, ed 7. Madrid: Elsevier, 2007, pp 3-18.

61. Maurer, M.H., Berger, C., Wolf, M., et al.: The proteome of human brain microdialysate. Proteome. Sci. 7, 2003.

62. Mellergard, P., Aneman, O., Sjogren, F., et al.: Changes in extracellular concentrations of some cytokines, chemokines, and neurotrophic factors after insertion of intracerebral microdialysis catheters in neurosurgical patients. Neurosurgery 2008; 62: 151-157.

63. Montaner, J., Molina, C.A., Monasterio, J., et al.: Matrix metalloproteinase-9 pretreatment level predicts intracranial hemorrhagic complications after thrombolysis in human stroke. Circulation 2003; 107: 598-603.

64. Moore, K.W., de Waal, M.R., Coffman, R.L., et al.: Interleukin-10 and the interleukin-10 receptor. Annu.Rev.Immunol. 2001; 19: 683-765.

65. Morganti-Kossmann, M.C., Rancan, M., Otto, VI., et al.: Role of cerebral inflammation after traumatic brain injury: a revisited concept. Shock 2001; 16: 165-177.

66. Morganti-Kossmann, M.C., Rancan, M., Stahel, P.F., et al.: Inflammatory response in acute traumatic brain injury: a double-edged sword. Curr. Opin. Crit Care 2002; 8: 101-105.

67. Mun-Bryce, S., Lukes, A., Wallace, J., et al.: Stromelysin-1 and gelatinase A are upregulated before TNF-alpha in LPS-stimulated neuroinflammation. Brain Res 2002; 933: 4249.

68. Nagase, H., Woessner, J.F., Jr.: Matrix metalloproteinases. J Biol. Chem 1999; 274: 21491-21494.

69. Petsko, G.A., Ringe, D.: Protein Structure and Function. Oxford University Press, 2006.

70. Petty, M.A., Lo, E.H.: Junctional complexes of the blood-brain barrier: permeability changes in neuroinflammation. Prog. Neurobiol. 2002; 311-323.

71. Plock, N., Kloft, C.: Microdialysis--theoretical background and recent implementation in applied life-sciences. Eur. J. Pharm. Sci. 2005; 25: 1-24.

72. Rabson, A., Roitt, I.M., Delves, P.J.: Adversarial strategies during infection, Really Essential Medical Immunology, ed $2^{\text {nd }}$. Oxford, UK: Blackwell Publishing Ltd., 2005, pp 114126.

73. Rosdahl, H., Hamrin, K., Ungerstedt, U., et al.: A microdialysis method for the in situ investigation of the action of large peptide molecules in human skeletal muscle: detection of local metabolic effects of insulin. Int J Biol Macromol 2000; 28: 69-73.

74. Rosdahl, H., Ungerstedt, U., Henriksson, J.: Microdialysis in human skeletal muscle and adipose tissue at low flow rates is possible if dextran-70 is added to prevent loss of perfusion fluid. Acta Physiol Scand 1997; 159: 261-262.

75. Rosenberg, G.A.: Matrix metalloproteinases in brain injury. J Neurotrauma 1995; 12: 833-842.

76. Rosenberg, G.A.: Matrix metalloproteinases in neuroinflammation. Glia 2002; 39: 279-291.

77. Rosenbloom, A.J., Ferris, R.L., Sipe, D.M., et al.: In vitro and in vivo protein sampling by combined microdialysis and ultrafiltration. J. Immunol. Methods 2006; 309: 5568.

78. Rosenbloom, A.J., Sipe, D.M., Weedn, V.W.: Microdialysis of proteins: performance of the CMA/20 probe. $\mathrm{J}$ Neurosci Methods 2005; 148: 147-153.

79. Ross, S.A., Halliday, M.I., Campbell, G.C., et al.: The presence of tumour necrosis factor in CSF and plasma after severe head injury. Br. J .Neurosurg. 1994; 8: 419-425.

80. Rossi, D., Zlotnik, A.: The biology of chemokines and their receptors. Annu. Rev. Immunol. 2000; 18: 217-242.

81. Rusakov, D.A., Kullmann, D.M.: Geometric and viscous components of the tortuosity of the extracellular space in the brain. Proc. Natl. Acad. Sci. U.S.A 1998; 95: 8975-8980.

82. Schmidt, O.I., Heyde, C.E., Ertel, W., et al.: Closed ead injury--an inflammatory disease? Brain Res.Brain Res. Rev. 2005; 48: 388-399. 
83. Schultz, J.S., Valentine, R., Choi, C.Y.: Reflection coefficients of homopore membranes: effect of molecular size and configuration. J. Gen. Physiol 1979; 73: 49-60.

84. Schutte, R.J., Oshodi, S.A., Reichert, W.M.: In vitro characterization of microdialysis sampling of macromolecules. Anal. Chem. 2004; 76: 6058-6063.

85. Shigemori, Y., Katayama, Y., Mori, T., et al.: Matrix metalloproteinase-9 is associated with blood-brain barrier opening and brain edema formation after cortical contusion in rats. Acta Neurochir. Suppl 2006; 96: 130-133.

86. Singhal, A., Baker, A.J., Hare, G.M., et al.: Association between cerebrospinal fluid interleukin-6 concentrations and outcome after severe human traumatic brain injury. J Neurotrauma 2002; 19: 929-937.

87. Sjogren, F., Svensson, C., Anderson, C.: Technical prerequisites for in vivo microdialysis determination of interleukin-6 in human dermis. Br J Dermatol 2002; 375-382.

88. Snyder, K.L., Nathan, C.E., Yee, A., et al.: Diffusion and calibration properties of microdialysis sampling membranes in biological media. Analyst 2001; 126: 1261-1268.

89. Somers, W., Stahl, M., Seehra, J.S.: 1.9 A crystal structure of interleukin 6: implications for a novel mode of receptor dimerization and signaling. EMBO J. 1997; 16: 989-997.

90. Stamatovic, S.M., Dimitrijevic, O.B., Keep, R.F., et al.: Inflammation and brain edema: new insights into the role of chemokines and their receptors. Acta Neurochir. Suppl 2006; 96: 444-450.

91. Sternlicht, M.D., Werb, Z.: How matrix metalloproteinases regulate cell behavior. Annu. Rev. Cell Dev. Biol. 2001; 17: 463-516.

92. Suehiro, E., Fujisawa, H., Akimura, T., et al.: Increased matrix metalloproteinase-9 in blood in association with activation of interleukin- 6 after traumatic brain injury: influence of hypothermic therapy. J Neurotrauma 2004; 21: 1706-1711.

93. Tang, A., Bungay, P.M., Gonzales, R.A.: Characterization of probe and tissue factors that influence interpretation of quantitative microdialysis experiments for dopamine. J. Neurosci. Methods 2003; 126: 1-11.

94. Tisdall, M.M., Smith, M.: Cerebral microdialysis: research technique or clinical tool. Br. J. Anaesth. 2006; 97: 18-25.

95. Torto, N., Laurell, T., Gorton, L., et al.: A study of a polysulfone membrane for use in an in-situ tunable microdialysis probe during monitoring of starch enzymatic hydrolysates. J. Membrane Sci. 1997; 130: 239-248.

96. Trickler, W.J., Miller, D.W.: Use of osmotic agents in microdialysis studies to improve the recovery of macromolecules. J. Pharm. Sci. 2003; 92: 1419-1427.

97. Ungerstedt, U., Rostami, E.: Microdialysis in neurointensive care. Curr. Pharm. Des 2004; 10: 2145-2152.

98. Vecil, G.G., Larsen, P.H., Corley, S.M., et al.: Interleukin-1 is a key regulator of matrix metalloproteinase- 9 expression in human neurons in culture and following mouse brain trauma in vivo. J Neurosci. Res 2000; 61: 212-224.

99. Vilalta, A., Sahuquillo, J., Poca, M..A., et al.: Posttraumatic contusions induce a strong brain inflammatory reaction. Poster. $13^{\text {th }}$ International Symposium on Intracranial Pressure and Brain Monitoring, San Francisco, USA 2007.

100. Vilalta, A., Sahuquillo, J., Rosell, A., et al.: Moderate and severe traumatic brain injury induce early overexpression of systemic and brain gelatinases. Intensive Care Med. 2008; 34: 1384-1392.

101. Voet, D., Voet, J.G.: Estructura tridimensional de las proteínas, Bioquímica, ed $3^{\text {rd }}$. Buenos Aires: Editorial Médica Panamericana S.A., 2006, pp 227-286.

102. Waelgaard, L., Pharo, A., Tonnessen, T.I., et al.: Microdialysis for monitoring inflammation: efficient recovery of cytokines and anaphylotoxins provided optimal catheter pore size and fluid velocity conditions. Scand. J. Immunol. 2006; 64: 345-352.

103. Wang, X., Lennartz, M.R., Loegering, D.J., et al.: Interleukin-6 collection through long-term implanted microdialysis sampling probes in rat subcutaneous space. Anal. Chem. 2007; 79: 1816-1824.

104. Wang, X., Mori, T., Jung, J.C., et al.: Secretion of matrix metalloproteinase-2 and -9 after mechanical trauma injury in rat cortical cultures and involvement of MAP kinase. J Neurotrauma 2002; 19: 615-625.

105. Wang, X., Stenken, J.A.: Microdialysis sampling membrane performance during in vitro macromolecule collection. Anal. Chem. 2006; 78: 6026-6034.

106. Wang, Y., Addess, K.J., Chen, J., et al.: MMDB: annotating protein sequences with Entrez's 3D-structure database. Nucleic Acids Res. 2007; 35: D298-D300.

107. Winter, C.D., Iannotti, F., Pringle, A.K., et al.: A microdialysis method for the recovery of IL-1beta, IL-6 and nerve growth factor from human brain in vivo. J. Neurosci. Methods 2002; 119: 45-50.

108. Winter, C.D., Pringle, A.K., Clough, G.F., et al.: Raised parenchymal interleukin-6 levels correlate with improved outcome after traumatic brain injury. Brain 2004; 127 : 315-320.

109. Yoon, S.I., Logsdon, N.J., Sheikh, F., et al.: Conformational changes mediate interleukin-10 receptor 2 (IL-10R2) binding to IL-10 and assembly of the signaling complex. J. Biol. Chem. 2006; 281: 35088-35096.

De Los Rios, J.A.; Sahuquillo, J.; Merino, M.A.; Poca, M.A.; Expósito, L.: Microdiálisis de alta resolución. Aspectos metodológicos y aplicación al estudio de la respuesta inflamatoria cerebral. Neurocirugía 2009; 20: 433-448.

Correspondencia postal: Juan Sahuquillo. Servicio de Neurocirugía. Hospital Universitario Vall d'Hebron. Universitat Autònoma de Barcelona, Paseo Vall d'Hebron 119-129. 08035, Barcelona. 
Comentario al trabajo Microdiálisis de alta resolución. Aspectos metodológicos y aplicación al estudio de la respuesta inflamatoria cerebral de De los Ríos y cols

De Los Ríos y colaboradores presentan una profunda y elaborada revisión de la literatura sobre la microdiálisis de alta resolución. En esta revisión se repasan los principios básicos de la técnica y se analizan los diferentes factores que intervienen en los procesos de recuperación de moléculas.

La técnica de microdiálisis constituye una herramienta con un gran potencial para profundizar en el estudio de los fenómenos neuroquímicos que tienen lugar en los pacientes neurocríticos. Sin embargo, no se puede afirmar que dicha técnica esté correctamente validada en el momento actual, a pesar de los artículos clínicos y experimentales recientemente publicados (1-3), y como señalan los autores en su conclusión, "antes de comenzar cualquier proyecto de investigación es necesario realizar estudios in vitro para conocer la recovery rate y poder así aproximar la validez a los resultados obtenidos en los pacientes". Dichos estudios experimentales definirán mejor parámetros como la tasa de recuperación, y podrán ser usados como referencia por otros investigadores, pero teniendo en cuenta que los resultados obtenidos in vitro solo podrán ser una estimación de lo que ocurre in vivo ya que dicha información experimental no es directamente extrapolable. Además es necesaria una cuidadosa selección de las moléculas que desean ser estudiadas mediante microdiálisis con catéteres de $100 \mathrm{kDa}$, reconociendo que las concentraciones de dichas moléculas deben ser interpretadas de una manera cautelosa y teniendo en consideración las limitaciones técnicas comentadas.

Otro aspecto importante a tener en cuenta con el empleo de este tipo de catéteres de alto cut-off, y que los autores comentan ampliamente, es la progresiva disminución en la capacidad de intercambio y por lo tanto de la recuperación. Se trata de un tema que se presta a debate, pues aún no existe suficiente evidencia experimental que permita determinar si un descenso de los niveles de las moléculas a estudio se debe a la progresiva disfunción del catéter por taponamiento a lo largo de los días, o si se debe a un descenso fisiológico de la respuesta inflamatoria, por ejemplo, en el caso de las citocinas.

En resumen, en esta revisión se exponen los fundamentos de la técnica de la microdiálisis de alta resolución. Dicha técnica nos proporcionará en el futuro una gran cantidad de información sobre la fisiopatología en los pacientes neurocríticos.

\section{Bibliografía}

1. Folkersma, H., Brevé, J.P., Tilders, F.J., et al: Cerebral microdialysis of interleukin-1B and IL-6: extraction efficiency and production in the acute phase after severe traumatic brain injury in rats. Acta Neurochir. 2008; 150: 1277-1284.

2. Hutchinson, P.J., O'Connell, M.T., Rothwell, N.J., et al.: Inflammation in human brain injury: intracerebral concentrations of IL-1 and their endogenous inhibitor IL-1ra. J Neurotrauma. 2007; 24: 1545-1557.

3. Mellegard, P., Aneman, O., Sjogren, F., et al.: Changes in extracellular concentrations of some cytokines, chemokines, and neurotrophic factors after insertion of intracerebral microdialysis catheters in neurosurgical patients. Neurosurgery. 2008; 62: 151-157.

J. Pérez-Barcena J. Ibáñez

Palma de Mallorca 